\title{
Current status of core and advanced adult gastrointestinal endoscopy training in Canada: Survey of existing accredited programs
}

\author{
Xin Xiong MDCM ${ }^{1}$, Alan N Barkun MDCM FRCPC FACP FACG FAGA MSc ${ }^{1,2}$, Kevin Waschke MDCM FRCPC ${ }^{1}$, \\ Myriam Martel BSc${ }^{1}$; and the Canadian Gastroenterology Training Program Directors*
}

\begin{abstract}
X Xiong, AN Barkun, K Waschke, M Martel; and the Canadian Gastroenterology Training Program Directors. Current status of core and advanced adult gastrointestinal endoscopy training in Canada: Survey of existing accredited programs. Can J Gastroenterol 2013;27(5):267-272.
\end{abstract}

OBJECTIVE: To determine the current status of core and advanced adult gastroenterology training in Canada.

METHODS: A survey consisting of 20 questions pertaining to core and advanced endoscopy training was circulated to 14 accredited adult gastroenterology residency program directors. For continuous variables, median and range were analyzed; for categorical variables, percentage and associated 95\% Cls were analyzed.

RESULTS: All 14 programs responded to the survey. The median number of core trainees was six (range four to 16). The median (range) procedural volumes for gastroscopy, colonoscopy, percutaneous endoscopic gastrostomy and sigmoidoscopy, respectively, were 400 ( 150 to 1000 ), 325 (200 to 1500 ), 15 (zero to 250 ) and 60 (25 to $300)$. Eleven of $13(84.6 \%)$ programs used endoscopy simulators in their curriculum. Eight of 14 programs (57\%) provided a structured advanced endoscopy training fellowship. The majority (88\%) offered training of combined endoscopic retrograde cholangiopancreatography (ERCP) and endoscopic ultrasonography. The median number of positions offered yearly for advanced endoscopy fellowship was one (range one to three). The median (range) procedural volumes for ERCP, endoscopic ultrasonography and endoscopic mucosal resection, respectively, were 325 (200 to 750 ), 250 ( 80 to 400 ) and 20 (10 to 63 ). None of the current programs offered training in endoscopic submucosal dissection or natural orifice transluminal endoscopic surgery. CONCLUSION: Most accredited adult Canadian gastroenterology programs met the minimal procedural requirements recommended by the Canadian Association of Gastroenterology during core training. However, a more heterogeneous experience has been observed for advanced training. Additional studies would be required to validate and standardize evaluation tools used during gastroenterology curricula.

\section{État actuel de la formation en endoscopie des programmes de gastro-entérologie accrédités au Canada}

OBJECTIF : Déterminer l'état actuel de la formation en gastroentérologie au Canada.

MÉTHODE : Un sondage de 20 questions sur la formation de base et avancée a été distribué aux directeurs des programmes de gastroentérologie accrédités au Canada. La médiane et l'étendue des variables continues, ainsi que le pourcentage et les intervalles de confiance à $95 \%$ des variables catégorielles, ont été analysés.

RÉSULTATS : Les 14 programmes ont répondu au sondage. La médiane du nombre des résidents en formation de base était de 6 (l'étendue étant de 4 à 16). Le nombre de gastroscopies, coloscopies, gastrostomies percutanées endoscopiques et sigmoïdoscopies était respectivement: 400 (150-1000), 325 (200-1500), $15(0-250)$ et 60 (25-300). Onze programmes $(84,6 \%)$ ont intégrés l'utilisation de simulateurs d'endoscopie dans leur formation. Huit programmes (57\%) offraient une formation avancée en endoscopie. La majorité (88\%) incluait la combinaison de cholangio-pancréatographie rétrograde endoscopique (CPRE) et d'endosonographie (EUS) durant la formation. La médiane du nombre de postes offerts par année était de 1 (1-3). Le nombre de CPRE, EUS et mucosectomies endoscopiques était respectivement: 325 (200-750), $250(80-400)$ et 20 (10-63). Aucun programme n'offrait de formation sur la dissection sous-muqueuse endoscopique ou la chirurgie endoscopique transluminale par orifice naturel.

CONCLUSION : En ce qui concerne la formation de base, la majorité des programmes canadiens satisfaisaient les normes recommandées par l'Association Canadienne de Gastroentérologie. Toutefois, on a observé une plus grande variabilité pour les programmes de formation avancée. De futures études seront nécessaires afin de valider les instruments d'évaluation utilisés dans la formation en endoscopie.

Key Words: Curriculum; Education; Endoscopy; Gastroenterology

Over the past decade, there have been many advances in technology and techniques in gastrointestinal endoscopy $(1,2)$. As technology has advanced, digestive endoscopy procedures have also become more complex. This evolution has required many programs to offer fellowships in advanced endoscopy to meet the ever-increasing needs of training new gastroenterologists who can satisfy the rapidly growing field of advanced endoscopy (3).

For the purpose of the present study, advanced endoscopy training included the following $(1,4)$ : endoscopic retrograde cholangiopancreatography (ERCP), endoscopic ultrasonography (EUS), endoscopic mucosal resection (EMR), advanced colon polypectomy, esophageal and enteral stent placement, device-assisted enteroscopy, endoscopic drainage of pancreatic pseudocyst, endoscopic removal of neoplasms of the ampulla of Vater, endoscopic submucosal dissection (ESD) and natural orifice transluminal endoscopic surgery (NOTES).

With the growing interest in improving gastroenterology (GI) training, there have been major changes in the credentialing process $(5-8)$. To ensure trainee competency, objectively measuring the quality of procedures has become increasingly more important in addition to meeting requirements of procedural volumes $(9,10)$. However, to date, there have been no published data regarding the evaluation of core and advanced GI training programs in Canada in the face of this trend-shifting era. Accordingly, we report the results of a survey assessing the current status of core and advanced adult GI endoscopy training programs in Canada.

\footnotetext{
${ }^{1}$ Divisions of Gastroenterology and ${ }^{2}$ Epidemiology Biostatistics and Occupational Health, McGill University Health Centre, McGill University, Montréal,

Québec. *Complete list of all Canadian Gastroenterology Training Program Directors is available at the conclusion of the article

Correspondence: Dr Alan N Barkun, Division of Gastroenterology, McGill University Health Centre, Montreal General Hospital site,

1650 Cedar Avenue, Room D16.125, Montreal, Quebec H3G 1A4. Telephone 514-934-8309, fax 514-834-8531, e-mail alan.barkun@muhc.mcgill.ca Received for publication October 18, 2012. Accepted November 5, 2012
} 
TABLE 1

List of respondent gastroenterology training programs and their respective current number of trainees in 2011 to 2012

\begin{tabular}{lcc}
\hline & \multicolumn{2}{c}{ Trainees, $\mathbf{n}$} \\
\cline { 2 - 3 } University & Core & Advanced \\
\hline Dalhousie University, Halifax, Nova Scotia & 6 & NA \\
Université Laval, Québec, Québec & 4 & NA \\
Université de Sherbrooke, Sherbrooke, Quebec & 6 & 1 \\
Université de Montréal, Montréal, Québec & 6 & NA \\
McGill University, Montreal, Quebec & 8 & 1 \\
University of Ottawa, Ottawa, Ontario & 7 & 1 \\
Queen's University, Kingston, Ontario & 4 & NA \\
University of Toronto, Toronto, Ontario & 16 & 3 \\
McMaster University, Hamilton, Ontario & 14 & 1 \\
Western University, London, Ontario & 6 & NA \\
University of Manitoba, Winnipeg, Manitoba & 4 & NA \\
University of Alberta, Edmonton, Alberta & 7 & NA* \\
University of Calgary, Calgary, Alberta & 8 & 1 \\
University of British Columbia, Vancouver, British & 5 & 1.5 \\
Columbia & &
\end{tabular}

*The University of Alberta did not provide any number of advanced trainees for 2011 to 2012. NA Not applicable to current year

\section{METHODS}

Surveyed population

A request to complete the survey was electronically mailed to all directors of accredited adult GI training programs in Canada, regardless of whether a third-tier program director position existed at a given institution. The program director either forwarded the e-mail to the advanced training director, if there was one at the given institution, or sought information pertaining to advanced training availability and content directly from appropriate colleagues and fellows.

\section{Survey instrument}

A survey instrument was created using a spreadsheet (Excel version 12.0, 2007, Microsoft Corporation, USA) and e-mailed as an attachment to all study participants. The items were developed by one of the coauthors (AN Barkun) and were based on perceived critical information pertaining to demographics, curriculum, funding, structure, and volume of exposure for both core and advanced endoscopic teaching programs. Subsections included 10 items on core endoscopic training and an additional 10 on advanced endoscopic training. The survey instrument is available in the Appendix.

\section{Statistical analysis}

The survey was composed of 20 questions with expected categorical response (Yes/No) as well as numerical response formats (for procedural volumes of exposure). Descriptive analysis was performed using median and range for continuous variables, and proportion and CI using the normal approximation of the binomial distribution for categorical variables.

\section{RESULTS}

Description of core training programs

All (14 of 14) accredited university-based Canadian adult GI residency programs participated in the survey (Table 1), although not all responded to all of the questions. The median number of core trainees in each program during the period from 2011 to 2012 was six (range four to 16). During 24 months of training, a median of 18.5 months (range seven to 24) were devoted to performing endoscopies. Eleven of 13 programs (85\%) responded that they offered use of endoscopy simulators for their trainees. In addition to teaching the cognitive skills of endoscopy, 12 of 14 programs (86\%) reported formally teaching core trainees the required quality indicators for colonoscopy (5).

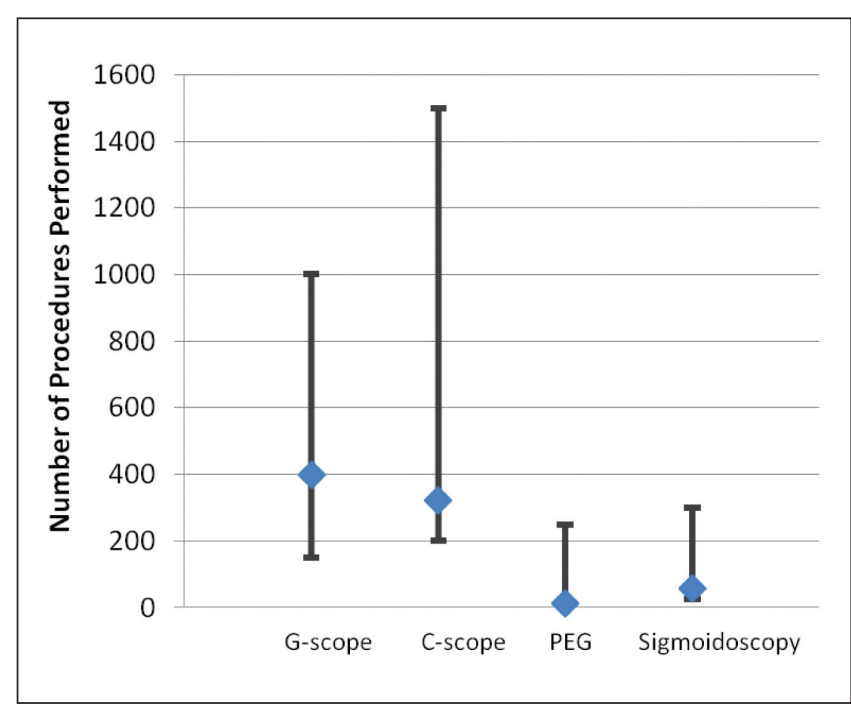

Figure 1) Reported endoscopic procedural volumes for core training programs ( $n=13$ respondent programs*, values expressed as median and their respective range). *One program did not provide numerical values because it recently implemented a record program and the data were not available at the time of the survey. C Colonoscopy; G Gastroscopy; PEG Percutaneous endoscopic gastroscopy

Reported endoscopic procedural volumes for core training programs over two years

Significant variability existed in the reported procedural volumes performed in core GI training. The median (range) procedural volumes for gastroscopy, colonoscopy, percutaneous endoscopic gastrostomy and sigmoidoscopy, respectively, were 400 (150 to 1000), 325 (200 to 1500 ), 15 (zero to 250 ) and 60 (25 to 300 ) (Figure 1). For gastroscopy and colonoscopy, the distribution of procedural volumes across different programs is presented in Figure 2A; for sigmoidoscopy, its distribution is illustrated in Figure 2B.

Among core training programs, five of 13 (38\%) offered opportunities to perform ERCP as part of their training. In the responses quantifying this experience, only three of these five programs provided numerical values, yielding a median result of 25 (range 20 to 120) ERCPs performed during core training. Similarly, six of 14 programs (43\%) offered opportunities to place enteric stents as part of core training. Of these, only three sites provided numerical values, yielding a median of five (range two to 20) stent placements.

\section{Description of advanced training programs}

Eight of 14 programs (57\%) reported offering a structured third (and sometimes fourth) year of advanced endoscopy training fellowship on a recurrent basis. Of these programs, the funding originated from $25 \%$ (two of eight) ad hoc, 13\% (one of eight) trainee, 13\% (one of eight) provincial government, $13 \%$ (one of eight) foreign government and $25 \%$ (two of eight) industry sponsorship (responses were not documented in one institution) (Figure 3).

The median number of positions offered on a yearly basis among the advanced endoscopy training programs was one, ranging from one to three positions yearly. Most ( $88 \%$ [seven of eight]) programs combined ERCP and EUS training as part of a single advanced endoscopy training fellowship. For EMR training, three of eight programs (38\%) did not provide a response. Of the programs that answered, three of five $(60 \%)$ offered EMR as part of the advanced fellowship.

Reported endoscopic procedural volumes for advanced training programs

The procedural volumes for ERCP, EUS and EMR, respectively, were 325 (200 to 750 ), 250 ( 80 to 400 ), and 20 (10 to 63) (Figure 4). For ERCP and EUS, the distribution of procedural volumes across different programs is presented in Figure 5. 


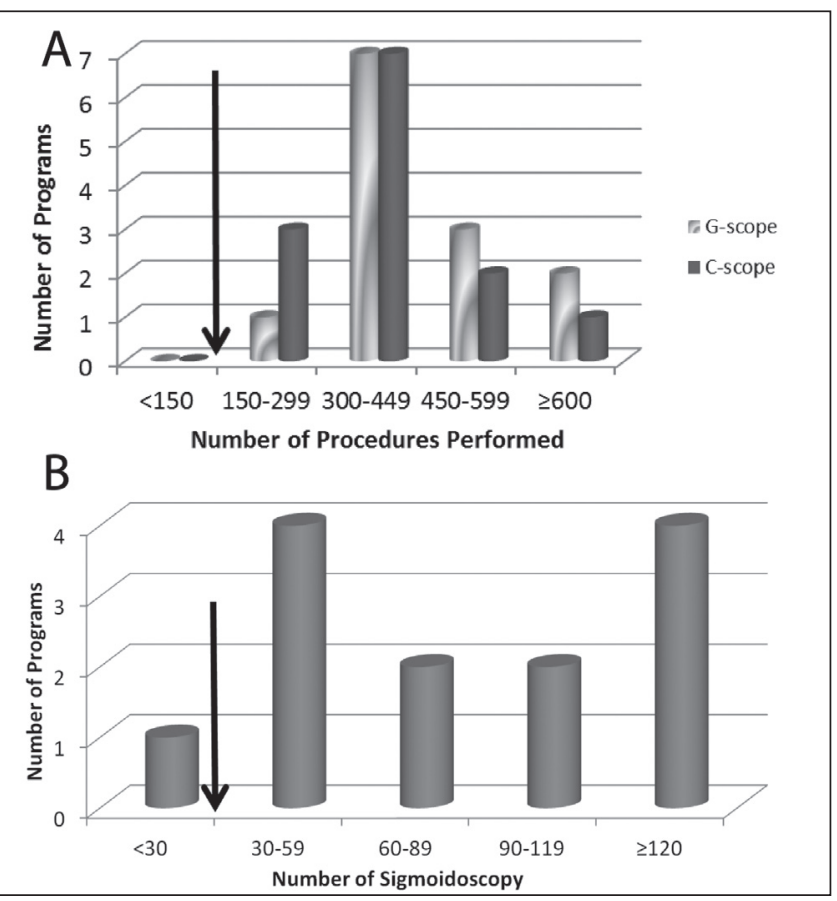

Figure 2) A Distribution of gastroscopy (G-scope) and colonoscopy (C-scope) performed during core gastroenterology training across universities. Arrow indicates the number of procedures required for appropriate credentialing for G-scope and C-scope (130 [8] and 140 [5], respectively). B Distribution of sigmoidoscopy performed during core gastroenterology training. Arrow indicates number of procedures required for appropriate credentialing for sigmoidoscopy (30 [7])

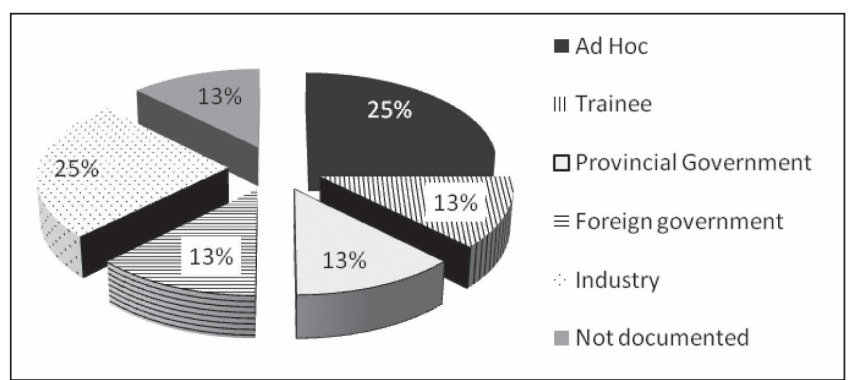

Figure 3) Funding source for the eight advanced endoscopy training fellowships offered in Canada

None of the current advanced endoscopy training programs offered any ESD or NOTES experience to advanced fellows. Moreover, none of the programs anticipated offering NOTES teaching as part of their training program in the foreseeable future.

\section{DISCUSSION}

There have been many advances in gastrointestinal endoscopy technology and techniques $(1,2)$. Training in GI has also undergone major changes. In addition to performing a requisite number of procedures to ensure competency, quality indicators have become an increasingly more critical criterion in the credentialing process $(9,10,12)$.

In our survey, a wide variety of reported procedural volumes was observed across different accredited programs in Canada. Given that the survey relied on voluntary reporting, these values were often approximations at best and should, therefore, be interpreted as such, with their inherent limitations. On the other hand, most programs have now developed methods of tracking procedural volumes more formally. For example, the initial estimate by one of the programs has been compared with subsequent true procedural data tracked using an electronic reporting database. The comparisons for each set,

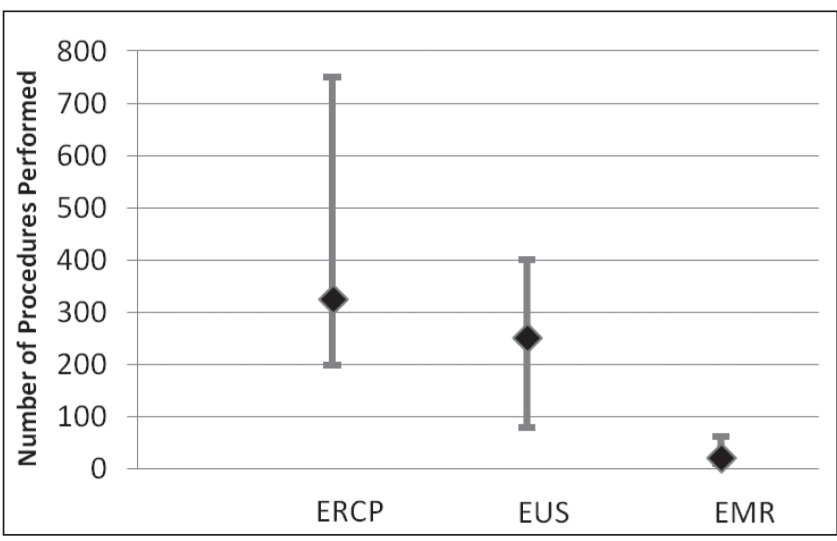

Figure 4) Reported endoscopic procedural volumes for advanced training programs ( $n=7$ responded program, values presented as median and range). *Note: One program did not provide data because it offered an advanced fellowship for the first year in 2011. EMR Endoscopic mucosal resection; ERCP Endoscopic retrograde cholangiopancreatography; EUS Endoscopic ultrasonography

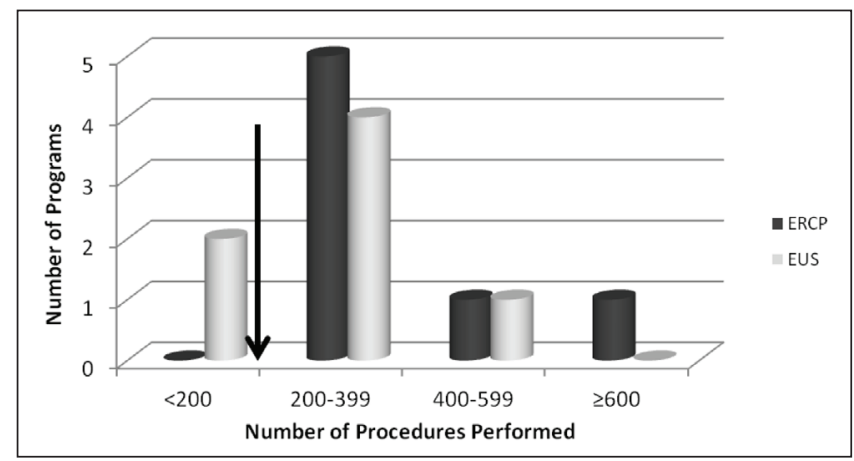

Figure 5) Distribution of endoscopic procedures performed during the advanced gastroenterology program. Arrow indicates the number of procedures required for credentialing: 200 for endoscopic retrograde cholangiopacreatography (ERCP [6,14]) and 190 for endoscopic ultrasonography (EUS [11])

respectively, were: gastroscopy - 500 in the survey versus 430 from tracking system (per cent accuracy 16\%); colonoscopy - 425 versus 308 (38\%); flexible sigmoidoscopy - 125 versus 85 (47\%); and ERCP - 750 versus 689 (9\%). This comparison demonstrates the significant variability in the accuracy of the procedural volume estimates reported in our survey. It would be interesting to collect and analyze the data from tracking electronic systems to ensure further, more formal and objective evaluations of GI programs locally. In addition, although the sample size was small and the point estimates carry with them wide corresponding CIs, the survey captures the entire population of trainees because all of the adult GI programs in Canada responded. The generalizability of these results to past and future years must, however, be considered.

Consistent with the corresponding Canadian Association of Gastroenterology (CAG) credentialing guidelines $(5,8)$, the procedural volumes for gastroscopy and colonoscopy reported by all programs respect the recommended minimum numbers necessary for each: 130 and 140, respectively (Figure 2A). However, for sigmoidoscopy, the reported value of one program $(7 \%)$ did not met the minimum requirement of 30 (7) (Figure 2B). This demonstrates a significantly more homogenous experience among core trainees in Canada compared with the United States (US) (13).

Of 14 programs, only eight (57\%) offer formal advanced endoscopy training. The number of fellowship positions yearly was reported as a median of one across each program. This appears to be surprisingly low given the ever-increasing advances in digestive endoscopy $(1,3)$ and 
may reflect limited funding opportunities. The financial support sources of advanced endoscopy fellowship, as indicated in Figure 3, reflect the current situation in GI fellowship training in Canada, revealing especially varied ways of acquiring funding, which may fluctuate from year to year for most sources.

In the programs that offer advanced training, the procedural volumes of ERCP exceeded the required minimum number of 180 (6) according to the CAG, and the threshold of 200 (14) proposed by the American Society of Gastrointestinal Endoscopy (ASGE) (6). However, for EUS, two of seven programs (29\%) reported values lower than the minimum suggested requirements (ie, 190) by the ASGE (11). The threshold number of EUS procedures to be performed vary according to the different types of indications (ie, mucosal tumours, pancreatobiliary, nonpancreatic, etc). A similar heterogeneity of experience was observed in advanced endoscopy training in the US (2). Interestingly, there is no current formal training in ESD or in NOTES, most likely secondary to insufficient case loads, lack of specialized equipment and, perhaps, lack of expertise.

In Canada, accreditation of residency training programs is performed by the Accreditation Committee appointed by the Royal College of Physicians and Surgeons of Canada (RCPSC). The objective of accreditation is "to improve the quality of postgraduate medical education" and "to provide a means for objective assessment of residency programs", which are accomplished with regular surveys every six years (15). For adult GI, a minimum of three years of internal medicine training is required before completion of a two-year dedicated training period. This includes at least 18 months of longitudinal inpatient and ambulatory experience in both academic and community centres, in addition to six months of either research or additional experience with adult or pediatric GI (15). During the training process, dedicated teaching faculty are required to supervise residents through endoscopy experience, and to provide teaching of basic and clinical sciences related to digestive tract pathologies (16). The CanMEDS roles are used for trainee evaluation, including medical expert, communicator, collaborator, manager, health advocate, scholar and professional aspects. Each of these aspects has specific goals and objectives that are published on the RCPSC website $(16,17)$. Residents receive certification through successful completion of an accredited curriculum and after successfully passing the RCPSC GI examination. No specific endoscopic criteria, including thresholds, are established by the RCPSC as a clear objective of training. This is amended by credentialing guidelines published by the CAG. In addition to GI training programs, general surgery residency also provides an opportunity to develop proficiency in gastroscopy and colonoscopy (18). Similarly, the RCPSC does not provide any specific endoscopic criteria. In contrast, formal guidelines to ensure competency are lacking for general surgery trainees, although the Canadian Association of General Surgery does encourage participation in quality assurance programs and continuing medical education to promote safety and quality of endoscopy (19).

After training in an accredited GI program in Canada, trainees are expected to become proficient in assuming the role of gastroenterologist in different clinical settings (17). The CAG has published credentialing guidelines for various endoscopic procedures to assist in determining competency $(5-8,20)$. The credentialing process is defined as the "process of assessing and validating the qualifications of a licensed independent practitioner to provide patient care" (11). In Canada, this is the responsibility of local institutions or facilities (20). It has been generally recommended that the competency of each endoscopic procedure be evaluated independently. Competency is usually defined as the "minimal level of skill, knowledge, and/or expertise, derived through training and experience, required to safely and proficiently perform a task or procedure" (14), without assistance or supervision. Specifically applied to gastrointestinal endoscopy, competency encompasses cognitive, technical and proficiency aspects. Current guidelines in credentialing have focused on all three components separately for an overall assessment of competency. There has been significant variation among institutions in the credentialing process in the absence of standardized methods for evaluating endoscopic privileges (20). The minimum number of procedures performed remains the only available objective quantification to assess technical aspects $(5-8,11,21)$ in the absence of additional formal measuring tools.

Sole procedural volume does not provide proper evaluation of the cognitive aspect of competency $(13,22,23)$, which includes assessment and thorough understanding of the gastrointestinal anatomy, physiology and pathology $(5-8,13,20,21,24)$. Moreover, the cognitive aspect of competency encompasses knowledge of the indications, contraindications, alternative procedures, informed consent process, complication rate, appropriate management of complications and recognition of pathology with appropriate therapeutic measures $(5-8,13,20,21,24)$. The shift in emphasis in the assessment of competency is apparent in current credentialing guidelines. For example (5), for colonoscopy, quality indicators used in credentialing guidelines include withdrawal time $>6$ min or $7 \mathrm{~min}$, mean time of procedure of $30 \mathrm{~min}$, cecal intubation success rates of $85 \%$ to $90 \%$ with appropriate photodocumentation, ileal intubation rates of $80 \%$ to $85 \%$ when there are adequate indications, measurement of the adenoma detection rates and assessment of complication rates.

Better established methods for evaluating the cognitive aspect, in addition to the procedural skill aspect, have been described in colonoscopy training. This includes the Direct Observation of Procedural Skills (DOPS) evaluation system used in United Kingdom (25-27), and the Mayo Colonoscopy Skills Assessment Tools (MCSAT) proposed in the US $(28,29)$. The DOPS includes the following aspects, detailed at the Joint Advisory Group on GI Endoscopy website (30): assessment, consent and communication; safety and sedation; endoscopic skills during insertion and withdrawal; and diagnostic and therapeutic ability. The MCSAT includes the following aspects (28): preprocedure - knowledge of indications as well as pertinent medical issues, and use of sedation; and procedural skills - degree of participation, farthest landmark reached without hands-on assistance, safe advancement technique, loop reduction technique, monitoring and management of patient discomfort, landmark recognition, adequate mucosal visualization and pathology identification. In a study by Sedlack (31), which used the MCSAT in the evaluation of competency in a single centre, a mean of 275 colonoscopies were needed before achieving competency compared with the minimal number of 140 recommended by the ASGE (32) and the CAG (5). On the other hand, the DOPS was assessed in the Canadian system and was found to have poor test-retest variability (26). Reasons for this observation may be the lack of familiarity with this tool by trainers. Hence, trainers will also need formal education on systematically using the newly developed evaluation system (33); the 'Training the Trainer' courses target, at least in part, such a need $(26,34)$. Although attempts have been made to apply these systems to other endoscopic procedures (27), none has been developed to this level of sophistication and validity. Interestingly, Dalhousie University (Halifax, Nova Scotia) has implemented the use of a DOPS approach for approximately one year. Their experience will surely provide more data to the validation process of using DOPS as formal evaluation tool.

Over the past decade, the endoscopy simulator is another instrument that has increasingly been used for training (35). In our survey, 11 of 13 programs $(84.6 \%)$ responded that they offer the use of endoscopy simulators for their trainees. Most studies on simulators in the literature (35-43) report its role in the preclinical phase of training, shortening the learning curve and improving performance in the early phase of novice endoscopy learners. On the other hand, there is limited supportive evidence of its role in the assessment of competency (44-46). The endoscopy training simulator resembles that of laparoscopy, for which there exists a variety of sophistication $(47,48)$. Similarly, it may be postulated that with improving technology, the arena of endoscopy simulators could evolve into the cornerstone of acquisition and assessment of digestive endoscopy skills during early training $(35,45)$. 


\section{CONCLUSION}

Most Canadian accredited core GI programs have met the minimum requirements of procedural volumes recommended by the CAG and ASGE credentialing guidelines. This demonstrates a more homogenous exposure than apparent in the US. On the other hand, more heterogeneous exposure has been noted in the advanced training, consistent with the trends seen in the US. There is currently no formal training for ESD and NOTES in Canada.

The training and evaluation process of gastrointestinal endoscopy has evolved significantly over the past decade, with increasing emphasis on assessment of overall competency, including cognitive as well as technical aspects. This is especially true in colonoscopy for which several evaluation tools have been developed. These require further validation, particularly in our system. There is an urgent need for continued development of objective instruments in digestive endoscopy learning, based on sound pedagogical principles, which will be remarkably useful in light of the growing number of emerging morbid procedures endoscopists are asked to perform.

Canadian Gastroenterology Training Program Directors: The Canadian Gastroenterology Training Program Directors are listed as follows: Dr Sunil Patel (Dalhousie University, Halifax), Dr Réjean Dubé (Université Laval, Quebec), Dr Annie Beaudoin (Université de Sherbrooke, Sherbrooke), Dr Mickaël Bouin (Université de Montréal, Montreal), Dr. Philip Wong (McGill University, Montreal), Dr Navaaz Saloojee (University of Ottawa, Ottawa), Dr Lawrence Hookey (Queen's University, Kingston), Dr. Maria Cino (University of Toronto, Toronto), Dr. Frances Tse (McMaster University, Hamilton), Dr Nilesh Chande (Western University, London), Dr Michael Cantor (University of Manitoba, Winnipeg), Dr Adriana Lazarescu (University of Alberta, Edmonton), Dr Shane Devlin (University of Calgary, Calgary) and Dr Nazira Chatur (University of British Columbia, Vancouver).

\section{APPENDIX: SURVEY INSTRUMENT}

The survey instrument that was circulated by electronic mail contains 20 questions, as follows:

1. How many core trainees in Gastroenterology do you currently have in your program?

2. How many months are spent performing endoscopies as part of core training rotations?

3. On average, how many gastroscopies will one of your typical trainees have performed by the end of the 2 years of core GI training?

4. On average, how many colonoscopies will one of your typical trainees have performed by the end of the 2 years of core GI training?

5. On average, how many PEGs will one of your typical trainees have performed by the end of the 2 years of core GI training?

6. On average, how many sigmoidoscopies will one of your typical trainees have performed by the end of the 2 years of core GI training?

7. Do you offer your core trainees the opportunity to use an endoscopy simulator (at your center or at a course) as part of their training (yes/no)?

8. Do you offer your core trainees the opportunity to perform ERCPs as part of their training ( $\mathrm{no}=0$, yes=average number)?

9. Do you offer your core trainees the opportunity to place enteric stents as part of their training ( $\mathrm{no}=0$, yes=average number)?

10. Are the quality indicators when reporting colonoscopy formerly taught to all core trainees (yes/no)?

11. Does you University offer every year a structured $(3 \mathrm{rd}+/-4$ th year) Advanced Endoscopic Training Fellowship (yes/no)?

12. What is the principal source of funding (from the Program / ad hoc / from the trainee)?
13. How many positions do you offer yearly, on average?

14. Do you combine ERCP and EUS training as part of a single Advanced Endoscopic Training Fellowship year (yes/no)?

15. On average, how many ERCPs will one of your Advanced Endoscopy Fellows perform during a year of Fellowship training $(\mathrm{O}=$ no ERCP training offered $)$ ?

16. On average, how many EUS will one of your Advanced Endoscopy Fellows perform during a year of Fellowship training $(\mathrm{O}=$ no EUS training offered $)$ ?

17. On average, how many EMRs will one of your Advanced Endoscopy Fellows perform during a year of Fellowship training $(\mathrm{O}=$ no EMR training offered $)$ ?

18. On average, how many ESDs will one of your Advanced Endoscopy Fellows perform during a year of Fellowship training $(0=$ no ESD training offered $)$ ?

19. On average, how many NOTES procedures will one of your Advanced Endoscopy Fellows see during a year of Fellowship training $(0=$ no NOTES done $)$ ?

20. Do you plan to offer NOTES teaching as part of your Advanced Endoscopy Program in the foreseeable future (yes/no)?

\section{REFERENCES}

1. Heller SJ, Tokar JL. Current status of advanced gastrointestinal endoscopy training fellowships in the United States. Advances in Medical Education and Practice 2011;2:25-34.

2. Azad J, Verma D, Kapadia A, Adler D. Can U.S. GI fellowship programs meet American Society for Gastrointestinal Endoscopy recommendations for training in EUS? A survey of U.S. GI fellowship program directors. Gastrointest Endosc 2006;64:235-41.

3. Trindade AJ, Faulx A, DiMaio CJ. Perspectives on the advanced endoscopy fellowship match. Gastrointest Endosc 2012;75:650-2.

4. Hawes RH. Advanced endoscopy and endosurgical procedures: Do we need a new subspecialty? Gastrointest Endosc Clin N Am 2007; 17:635-9, ix.

5. Romagnuolo J, Enns R, Ponich T, et al. Canadian credentialing guidelines for colonoscopy. Can J Gastroenterol 2008;22:17-22.

6. Springer J, Enns R, Romagnuolo J, et al. Canadian credentialing guidelines for endoscopic retrograde cholangiopancreatography. Can J Gastroenterol 2008;22:547-51.

7. Enns R, Romagnuolo J, Ponich T, et al. Canadian credentialing guidelines for flexible sigmoidoscopy. Can J Gastroenterol 2008;22:115-20.

8. Ponich T, Enns R, Romagnuolo J, et al. Canadian credentialing guidelines for esophagogastroduodenoscopy. Can J Gastroenterol 2008;22:349-54.

9. Armstrong D, Barkun A, Bridges R, et al. Canadian association of gastroenterology consensus guidelines on safety and quality indicators in endoscopy. Can J Gastroenterol 2012;26:17-31.

10. Elta GH. GI training: Where are we headed. Am J Gastroenterol 2011;106:395-7.

11. Eisen GM, Dominitz JA, Faigel DO, et al. Guidelines for credentialing and granting privileges for endoscopic ultrasound. Gastrointest Endosc 2001;54:811-4.

12. Koch AD, Haringsma J, Schoon EJ, De Man RA, Kuipers EJ. Competence measurement during colonoscopy training: The use of self-assessment of performance measures. Am J Gastroenterol 2012;107:971-5.

13. Sharma VK, Coppola AG Jr, Raufman JP. A survey of credentialing practices of gastrointestinal endoscopy centers in the United States. J Clin Gastroenterol 2005;39:501-7.

14. Eisen GM, Baron TH, Dominitz JA, et al. Methods of granting hospital privileges to perform gastrointestinal endoscopy. Gastrointest Endosc 2002;55:780-3.

15. Subspecialty Training Requirements in Adult and Pediatric Gastroenterology. $2011<$ http://rcpsc.medical.org/residency/ certification/training/gastroenterology_e.pdf> (Accessed September 25, 2012).

16. Specific Standards of Accreditation for Residency Programs in Adult Gastroenterology. $2011<$ http://rcpsc.medical.org/residency/ accreditation/ssas/gastroadult_e.pdf $>$ (Accessed September 25, 2012). 
17. Objectives of Training in the Subspecialty of Gastroenterology. $2011<\mathrm{http}: / / \mathrm{rcpsc}$.medical.org/residency/certification/objectives/ gastroenterology_e.pdf> (Accessed September 25, 2012).

18. Objectives of Training in the Specialty of General Surgery. $2010<$ http://rcpsc.medical.org/residency/certification/objectives/ gen_surg_e.pdf> (Accessed September 25, 2012).

19. Reid S, George R, Warnock G, et al. Canadian Association of General Surgeons statement on endoscopy. Can J Surg 2011;54:295.

20. Armstrong D, Enns R, Ponich T, et al. Canadian credentialing guidelines for endoscopic privileges: An overview. Can J Gastroenterol 2007;21:797-801.

21. Ang T, Cheng J, Khor J, et al. Guideline on training and credentialing in endoscopic retrograde cholangiopancreatography. Singap Med J 2011;52:654-7.

22. Cass OW, Freeman ML, Peine CJ, Zera RT, Onstad GR. Objective evaluation of endoscopy skills during training. Ann Intern Med 1993;118:40-4.

23. Cass OW. Training to competence in gastrointestinal endoscopy: A plea for continuous measuring of objective end points. Endoscopy 1999;31:751-4.

24. Mishra G. Competence and credentialing in endoscopy. Gastroenterol Hepatol (NY) 2007;3:917-9.

25. Barton R. Accrediting competence in colonoscopy: Validity and reliability of the UK Joint Advisory Group/NHS Bowel Cancer Screening Programme accreditation assessment. Gastrointest Endosc 2008;67:AB77.

26. Mohamed R, Shaheen A, Raman M. Evaluation of colonoscopy skills - how well are we doing? Can J Gastroenterol 2011;25:198-200.

27. Barton JR, Corbett S, van der Vleuten CP. The validity and reliability of a Direct Observation of Procedural Skills assessment tool: Assessing colonoscopic skills of senior endoscopists. Gastrointest Endosc 2012;75:591-7.

28. Sedlack RE. The Mayo Colonoscopy Skills Assessment Tool: Validation of a unique instrument to assess colonoscopy skills in trainees. Gastrointest Endosc 2010;72:1125-33.e3.

29. Cohen J. Objective longitudinal performance measurement using the Mayo Colonoscopy Skills Assessment Tool: A step in the right direction. Gastrointest Endosc 2010;72:1134-7.

30. Formative DOPS Assessment Form - Colonoscopy and Flexible Sigmoidoscopy. $2010<$ www.thejag.org.uk/downloads/DOPS\%20 Forms/\%5CFormative\%20DOPS\%20Assessment\%20Form \%20 -\%20Colonoscopy\%20and\%20FS.pdf> (Accessed September 25, 2012).

31. Sedlack RE. Training to competency in colonoscopy: Assessing and defining competency standards. Gastrointest Endosc 2011;74:35566;366.e1-366.e2.

32. Wexner SD, Litwin D, Cohen J, et al. Principles of privileging and credentialing for endoscopy and colonoscopy. Gastrointest Endosc 2002;55:145-8.
33. Coderre S, Anderson J, Rostom A, McLaughlin K. Training the endoscopy trainer: From general principles to specific concepts. Can J Gastroenterol 2010;24:700-4.

34. Hollingworth R, Dube C. The Canadian Association of Gastroenterology Endoscopy Quality Initiative: Leading the wave. Can J Gastroenterol 2009;23:506-9.

35. Cantu P, Penagini R. Computer simulators: The present and near future of training in digestive endoscopy. Dig Liv Dis 2012;44:106-10.

36. Leung J, Lim B, Ngo C, et al. Head-to-head comparison of practice with endoscopic retrograde cholangiopancreatography computer and mechanical simulators by experienced endoscopists and trainees. Dig Endosc 2012;24:175-81.

37. Lightdale J, Newburg A, Mahoney L, Fredette M and Fishman L. Fellow perceptions of training using computer-based endoscopy simulators. Gastrointest Endosc 2010;72:13-8.

38. Kim S, Spencer G, Makar G, et al. Lack of a discriminatory function for endoscopy skills on a computer-based simulator. Surg Endosc Other Intervent Tech 2010;24:3008-15.

39. Kumar P, Tse F. Assessing the learning curve for the acquisition of colonoscopy skills on a computer based endoscopy simulator. Can J Gastroenterol 2009;23(Suppl A). Canadian Digestive Diseases Week, February 27 to March 2, Banff, Alberta. (Abst)

40. Haycock A, Koch AD, Familiari P, et al. Training and transfer of colonoscopy skills: A multinational, randomized, blinded, controlled trial of simulator versus bedside training. Gastrointest Endosc 2010;71:298-307.

41. Desilets D, Banerjee S, Barth B, et al. Endoscopic simulators. Gastrointest Endosc 2011;73:861-7.

42. Matthes K, Thakkar SJ. "See one, simulate one, do one, teach one"- the value of hands-on simulator training in interventional endoscopy. Tech Gastrointest Endosc 2011;13:111-2.

43. Aslanian H. Ain't nothing like the real thing? Simulators in endoscopy training. Gastrointest Endosc 2012;75:261-2.

44. Sedlack RE. Competency assessment: It's time to expect more from our simulator. Dig Liv Dis 2012;44:537-8.

45. Maiss J, Naegel A, Hochberger J. The European experience current use of simulator training in Europe. Tech Gastrointest Endosc 2011;13:126-31.

46. Haycock A. Moving from training to competency testing. Tech Gastrointest Endosc 2011;13:155-60.

47. Botden SM, Jakimowicz JJ. What is going on in augmented reality simulation in laparoscopic surgery? Surg Endosc 2009;23:1693-700.

48. Thijssen AS, Schijven MP. Contemporary virtual reality laparoscopy simulators: Quicksand or solid grounds for assessing surgical trainees? Am J Surg 2010;199:529-41. 


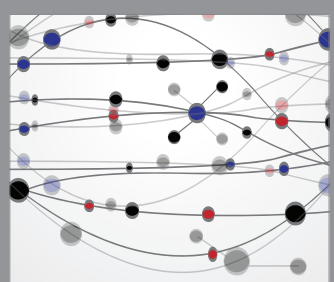

The Scientific World Journal
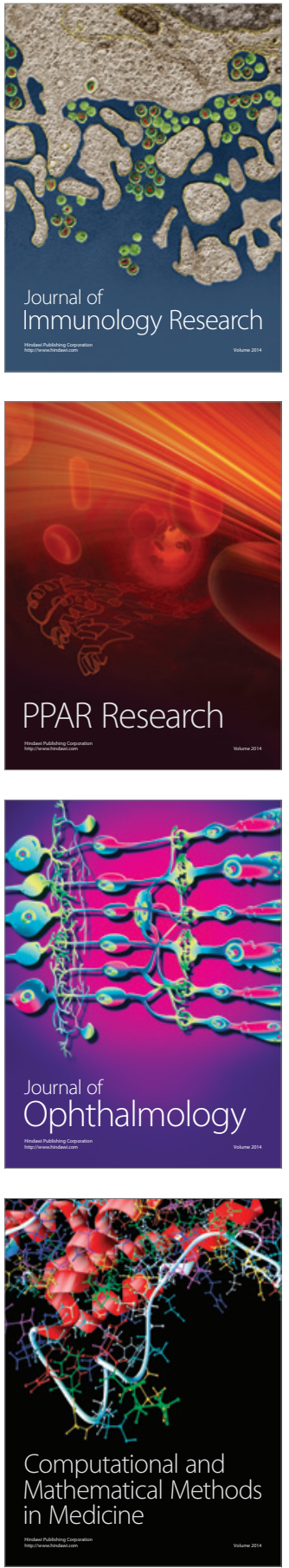

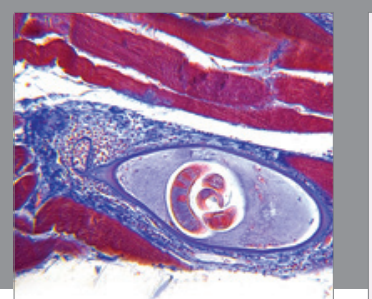

Gastroenterology Research and Practice

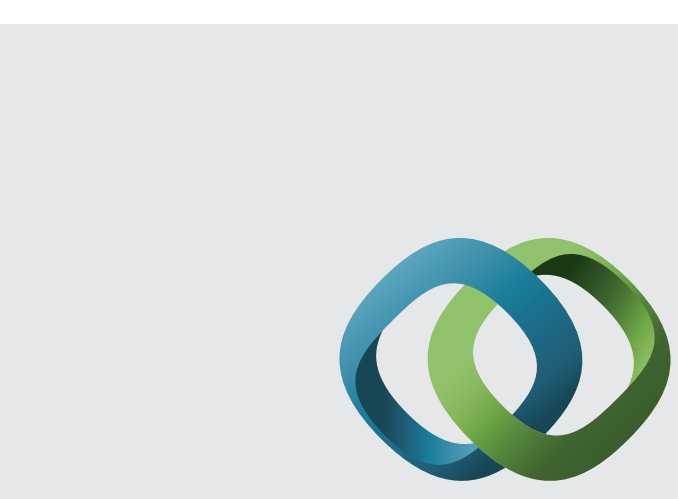

\section{Hindawi}

Submit your manuscripts at

http://www.hindawi.com
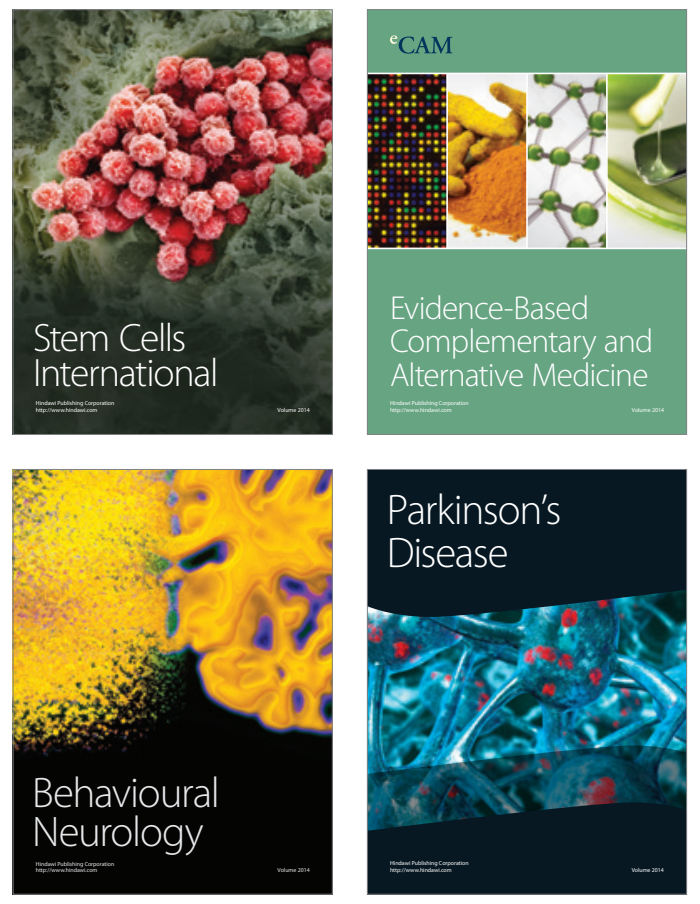
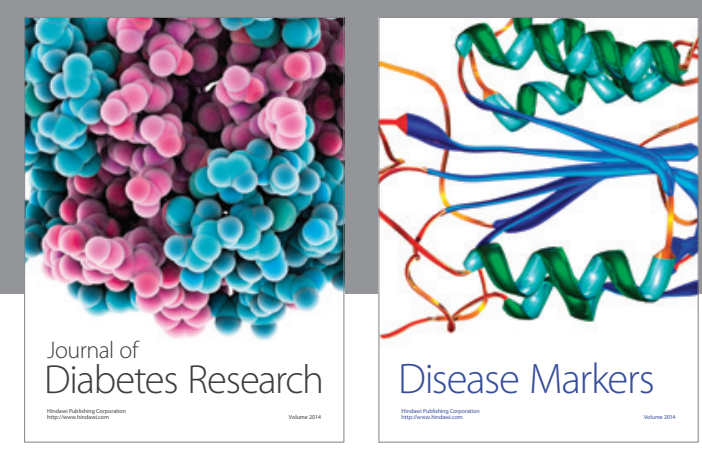

Disease Markers
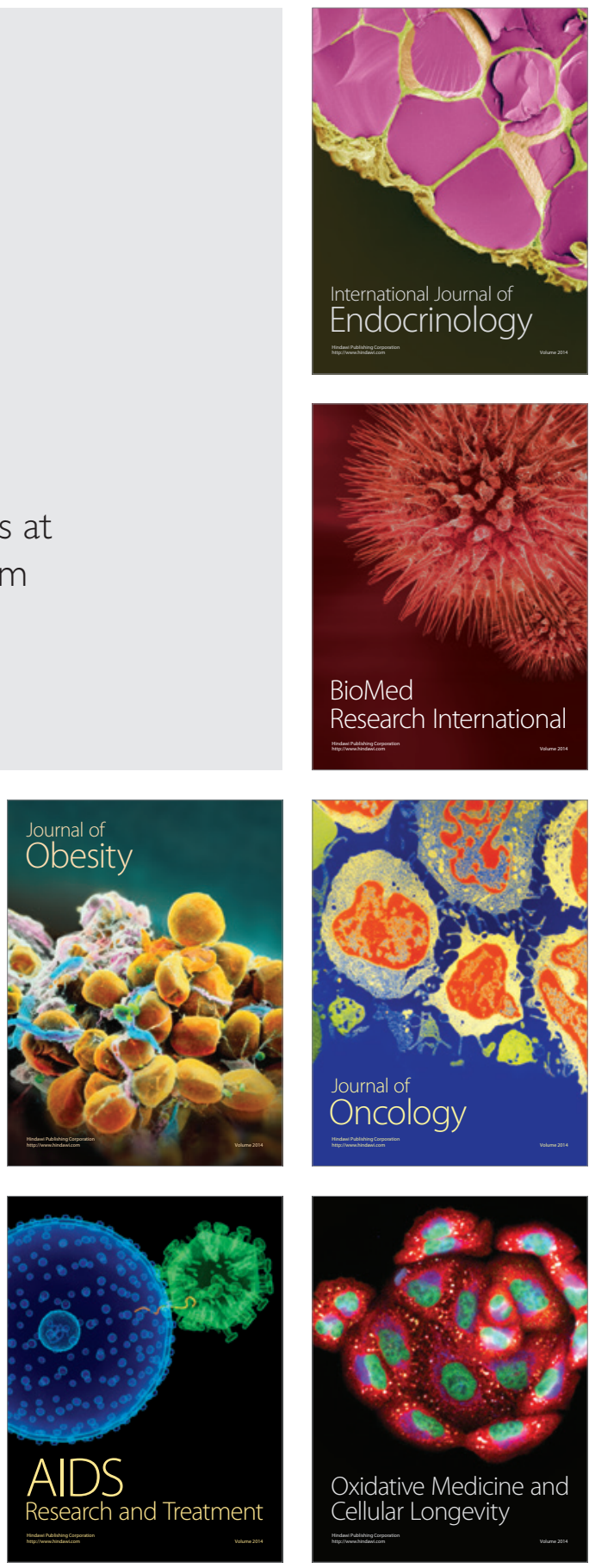